\title{
O MÉTODO (AUTO)BIOGRÁFICO COMO DISPOSITIVO DE FORMAÇÃO NA INICIAÇÃO CIENTÍFICA
}

\author{
- FERNANDA NOGUEIRA MACENA \\ http://orcid.org/0000-0001-9545-0124 \\ Universidade Estadual do Sudoeste da Bahia \\ - ÉLICA LUIZA PAIVA \\ https://orcid.org/0000-0001-7708-6445 \\ Universidade Estadual do Sudoeste da Bahia
}

RESUMO Este artigo traz as compreensões sobre o processo formativo de ex -estudantes do curso de Comunicação Social com habilitação em Jornalismo da Universidade Estadual do Sudoeste da Bahia (UESB), que participaram da Iniciação Científica (IC) no Edital UESB no 031/2016 promovida pelo grupo de estudos e pesquisa Narrativas, formação e experiência (Naforme) no projeto $A$ travessia da formação em Jornalismo: narrativas de vida e experiência em curso. Esta investigação objetiva compreender no que participar da IC imbrica no processo formativo do estudante e na escolha do tema e no desenvolvimento do seu Trabalho de Conclusão de Curso (TCC). Para tanto, utilizamos o método (auto)biográfico e como técnica de pesquisa a entrevista aberta com quatro ex-estudantes que participaram da IC e já concluíram seus TCCs. Assim, ao final, esta pesquisa possibilitou compreender a importância que o participar da IC e de grupo de estudo e pesquisa tem, na formação profissional/humana dos estudantes $\mathrm{e}$ o quanto isso influencia nas escolhas futuras; tanto no âmbito acadêmico, como o tema e desenvolvimento do TCC, quanto para à ampliação de seus horizontes formativos.

Palavras-chave: Experiência. Formação. (Auto)Biográfico. Iniciação Científica. TCC.

\section{ABSTRACT THE (AUTO)BIOGRAPHICAL METHOD AS A TRAINING DEVICE IN SCIENTIFIC INITIATION}

This paper presents comprehensions about the graduating process of the journalism qualified social communication form students from Universidade Estadual do Sudoeste da Bahia (UESB), which attended Scientific Research notice UESB no 031/2016 promoted by the studies 
and research group Narratives, Formation and Experience (Naforme) in the project The crossing of training in Journalism: narratives of life and ongoing experience. The main goal of this investigation is to comprehend the impact of Scientific Research on the student graduating process, to the final work theme choosing and its development. For this, we applied the (auto)biographic method, and as a research technique the open interview with four students who attended scientific research and have already concluded their final work. Therefore, in the end, this research allowed to comprehend the importance of attending scientific research and study and research group in the professional/human training and how much it influences in future choices; both in academics field, such as in theme and development of the final work, as expanding your formative horizons.

Keywords: Experience. Formation. (Auto)biographic. Scientific Research. Final Work.

\section{RESUMEN EL MÉTODO (AUTO)BIOGRÁFICO COMO DISPOSITIVO DE FORMACIÓN EM LA INICIACIÓN CIENTÍFICA}

Este artículo trae la comprensión sobre el proceso formativo de ex estudiantes del curso de Comunicación Social con calificación de Periodismo de la Universidad Estatal del Suroeste de Bahía (UESB), que participaron en la Iniciación Científica (IC) en el Aviso UESB no 031/2016, promovida por el grupo de estudio e investigación Narrativa, formación y experiencia (Naforme) en el proyecto El cruce de la formación periodística: narraciones de vida y experiencia em curso. Esta investigación objetiva comprender en qué participar en la Iniciación Científica imbrica en el proceso formativo del alumno y en la elección del tema y en el desarrollo de su Documento de Conclusión del Curso. Por lo tanto, utilizamos el método (auto)biográfico y como técnica de investigación la entrevista abierta con cuatro ex estudiantes que participaron en el IC y ya completaron sus Documento de Conclusión del Curso. Por lo tanto, al final, esta investigación permitió comprender la importancia que la participación en el IC y en el grupo de estudio e investigación tienen, en la formación profesional/humana de los estudiantes, y cuánto influye en sus opciones futuras; tanto en el ámbito académico, como el tema y el desarrollo del TCC, como para la expansión de sus horizontes formativos.

Palabras Clave: Experiencia. Formación. (Auto)Biográfico. Iniciación Científica. Documento de Conclusión del Curso. 


\section{Introdução}

Este artigo traz a narrativa das nossas compreensões sobre percursos formativos de ex -estudantes do curso de Comunicação Social com habilitação em Jornalismo da Universidade Estadual do Sudoeste da Bahia (UESB), que participaram da Iniciação Científica (IC) no Edital ${ }^{1}$ no $031 / 2016$, promovida pelo grupo de estudos e pesquisa Narrativas, formação e experiência (Naforme), no projeto $A$ travessia da formação em Jornalismo: narrativas de vida e experiência em curso. 0 projeto intenciona compreender como acontece a formação dos estudantes de/em Jornalismo - por meio de entrevistas gravadas e filmadas de alunos egressos, concluintes, ex-alunos e professores do curso - ao realizar um videodocumentário com e a partir dos conteúdos coletados. Vale salientar que, cada pesquisador desse projeto é aluno ou ex-aluno do curso de Comunicação Social com habilitação em Jornalismo da UESB. Sendo assim, esses também são considerados como pessoas pesquisadas, pela coordenação do projeto, e tiveram a sua trajetória de pesquisa filmada com o objetivo de se fazer um filme etnográfico sobre o trabalho dos pesquisados na IC.

Esta investigação objetiva compreender no que participar da IC imbricou no processo formativo, na escolha do tema e no desenvolvimento dos Trabalhos de Conclusão de Curso (TCCS) dos ex-estudantes² Agulhas Negras, Monte Roraima, Pedra Azul e Pedra do Céu que participaram como pesquisadores no/do projeto acima mencionado. Para tecer as interpretações intencionadas nesse objetivo, esta pesquisa se utiliza do método biográfico

1 A construção do artigo não era requisito obrigatório desse Edital.

2 Optamos por não utilizar os nomes reais dos pesquisados no intuito de preservar as suas identidades, portanto, será empregado nomes fictícios. Os nomes escolhidos foram os de montanhas do Brasil, que assim como os ex-estudantes pesquisados, estão em constantes (trans)formações. de Franco Ferrarotti (2010) também chamado de (auto)biográfico ou das histórias de vida e, como técnica de coleta de dados, entrevistas abertas com os ex-estudantes acima mencionados.

O método biográfico, que tem abordagem quase inteiramente qualitativa, possibilita que haja formação tanto para o pesquisador quanto para o pesquisado. Ao colher as narrativas de vida dos pesquisados, o que pode ser feito também por meio de entrevistas abertas (FERRAROTTI, 2010), o pesquisador tem a oportunidade de se formar pela heterobiografia (DELORY-MOMBERGER, 2008), enquanto os pesquisados se colocam num movimento autoformativo ao se tornarem personagens principais de suas próprias narrativas de vida, no decorrer da contação de suas experiências vivenciadas no tempo da IC. Tendo essas e outras premissas do método biográfico, discutidas no decorrer deste artigo, as entrevistas foram realizadas tendo quatro questões norteadoras que ajudaram a recortar o trajeto formativo em investigação.

As entrevistas abertas com os ex-estudantes do curso de Comunicação Social com habilitação em Jornalismo da UESB e ex-integrantes da IC do Naforme foram realizadas à distância, visto que os entrevistados, no período da pesquisa, estavam em cidades diferentes e não havia a possibilidade de se reunirem presencialmente. Assim, as perguntas foram conduzidas pelo pesquisador de forma escrita e enviadas aos pesquisados, sendo que três deles responderam por áudio e um optou por redigir as respostas. 0 intuito dos questionamentos feitos aos pesquisados foi de possibilitar que falassem sobre o que compreendem a respeito da IC; suas experiências enquanto pesquisadores do/no Naforme; a IC em seu processo formativo universitário e, por fim, se a escolha de seus temas e desenvolvimento de 
seus TCCs fazem inferências ou dialogam diretamente com os temas e autores trabalhados na IC.

Para tanto, esta pesquisa foi embasada em Nóvoa e Finger (2010), que dialogam sobre a utilização do método (auto)biográfico como dispositivo de formação e de autoformação. Ainda desse livro, o capítulo de autoria de Franco Ferrarotti traz, para este texto, a contribuição que reafirma um dos pressupostos base para a utilização desse método que é o reconhecimento da subjetividade enquanto uma forma de conhecimento. Destaca-se também as discussões construídas por Delory-Momberger (2008), no que se refere ao movimento socioeducativo, ao cunhar o conceito do que seria as histórias de vida em formação, e como esse modelo prevaleceu na sociedade. Ancoramos também as discussões em Josso (2010), que aborda sobre a importância da formação que emerge com e nas narrativas de vida. A obra de Paiva (2018) colabora com esta pesquisa ao trazer a compreensão do que emerge da formação, através de narrativas de histórias de vida de velhos do Povoado do Maracujá, produzidas por adolescentes deste mesmo lugar. Halbwachs (1990), ao discutir questões sobre a memória coletiva, contribui no que concerne o seu entendimento de que a memória individual existe sempre e a partir de uma memória coletiva, visto que as lembranças podem ser reconstruídas ou simuladas a partir da memória coletiva. Entre os demais autores que embasam esta pesquisa dialogamos com Larrosa (2002), que apresenta uma forma de pensar a educação através da experiência/sentido; Souza (2007), que discute se há uma ligação entre as (auto)biografias, a história da educação e as práticas de formação e Passeggi (2011), que busca trazer um novo sentido para a experiência no âmbito da formação de formadores, entre outras pesquisas, também foram necessárias para a elaboração do artigo.

\section{O método (auto)biográfico}

O método biográfico ou das histórias de vida, também conhecido como (auto)biográfico ou das narrativas de histórias de vida, consiste em cada pessoa buscar uma reflexão sobre o seu próprio processo de formação, e a partir disso, compreender as etapas e identificar os momentos que foram formadores no decorrer de sua vida através da narrativa do vivido. Ao narrar sua história de vida, a pessoa consegue refletir sobre momentos que reconhece ter sido formadores em sua vida ou identificar vivências formadoras enquanto lembra e narra, as quais antes não the apareciam como tal. Isso nem sempre acontece no processo formativo escolar, uma vez que a quantidade de conteúdos que são discutidos em sala de aula dificulta que os estudantes tenham tempo para assimilar o que foi trabalhado, o que o impede de reconhecer que toda aprendizagem é autoaprendizagem, pois perpassa a forma de lidar com a vida. Sobre essa questão, Nóvoa e Finger (1988, p. 116) afirmam que:

As histórias de vida e o método (auto)biográfico integram-se no movimento actual que procura repensar as questões da formação, acentuando a idéia que 'ninguém forma ninguém' e que 'a formação é inevitavelmente um trabalho de reflexão sobre os percursos de vida'.

Nesse sentido, o método (auto)biográfico proporciona ao pesquisador e ao pesquisado (re)pensar sobre o seu percurso de vida, o qual está em análise na pesquisa, e favorece a compreensão de que o processo formativo é multirreferencial e acontece independente se aquele que lembra se dá conta ou não, que aprendeu. Que o processo formativo é infinito em sua finitude, enquanto movimento próprio da vida. Mas, que quando a lembrança traz ao que lembra, um pertencimento de um saber que se sabe, emerge na narrativa do vivido o que Josso (2004, p. 223) chama de "a face visí- 
vel da formação". Souza (2007), ainda, afirma que para realizar uma pesquisa relacionada à educação é comum a preferência pelo método (auto)biográfico e as narrativas de formação, como forma de investigação, uma vez que nesse processo a pessoa que está pesquisando também está se formando através das narrativas de vida do outro.

Nessa perspectiva, Souza (2007) utiliza conceitos de Josso (2004), para falar que o método (auto)biográfico concebe uma validade maior para aquilo que é subjetivo para a pessoa, o seu modo de pensar, a sua interpretação sobre sua trajetória de vida, a qual ela usa como um modo de produzir conhecimento. 0 método também trabalha com a intersubjetividade, uma comunicação entre as consciências individuais, que possibilita uma maior interpretação e sentido as narrativas contadas. Esses diálogos funcionam como um suporte para interpretação de algo e conferem significados para as suas próprias narrativas, pois, para Souza (2007, p. 66), “[...] a abordagem biográfico-narrativa pode auxiliar na compreensão do singular/universal das histórias, memórias institucionais e formadoras dos sujeitos em seus contextos [...]". Dessa forma, essa abordagem pode auxiliar o pesquisador a compreender melhor sobre os percursos vividos pelos pesquisados, pois é a partir desta narração da história de vida, que o investigado poderá assimilar como aconteceu a sua formação.

Segundo Ferrarotti (2010), a biografia deriva quase que inteiramente do domínio qualitativo. A abordagem qualitativa é voltada para estudar as particularidades do pesquisado, as suas subjetividades, e como o método (auto) biográfico tem esse processo formativo, a metodologia quantitativa e experimental não contemplam o objetivo dele. Nesse sentido, Souza (2007), acredita que enquanto o pesquisador estiver atentamente ouvindo as narrativas de vida do pesquisado, inevitavelmente, o todo ouvido e interpretado acaba refletindo em seu processo formativo. Assim, nas histórias de vida, ainda que a conversa seja conduzida de forma sútil pelo pesquisador, é o pesquisado que irá decidir o que será contado ou não sobre a sua narrativa de vida; para isso, o investigado não precisará seguir uma ordem lógica das situações vividas, pois irá narrar da forma que lembra, a trajetória percorrida por ele. Souza (2007, p. 67), acredita que:

As variadas tipificações ou classificações no uso do método biográfico inscrevem-se no âmbito de pesquisas sócio-educacionais como uma possibilidade de, a partir da voz dos atores/ atrizes sociais, recuperar a singularidade das histórias narradas por sujeitos históricos, socioculturalmente situados, garantindo às mesmas o seu papel de construtores da história individual/coletiva intermediada por suas vozes.

Ainda, de acordo com Ferrarotti (2010), a particularidade do método biográfico é dividida em: materiais biográficos primários ou as narrativas (auto)biográficas, no qual o pesquisador realiza uma entrevista frente a frente com o pesquisado; e materiais biográficos secundários, em que utiliza-se de documentos biográficos que não foram aproveitados pelo investigador em sua pesquisa com o entrevistado nos moldes primários, como fotografias, cartas, documentos oficiais, narrativas e testemunhos escritos, entre outros. Ainda que nos materiais biográficos secundários seja possível descobrir parte das histórias de vida do investigado, é por meio da conversação que o investigador conseguirá manter uma comunicação recíproca com a pessoa que está sendo pesquisada.

Nessa perspectiva, Ferrarotti (2010) defende a utilização dos materiais biográficos primários ou as narrativas (auto)biográficas como corpus para análise, visto que traz a subjetividade dos autores-personagens pesquisados, para a baila da interpretação. Dessa forma, é 
possivel ter uma maior aproximação entre 0 pesquisador e o pesquisado, visto que uma entrevista presencial facilita a comunicação entre eles; pois, a partir desse diálogo, que o narrador conseguirá contar as suas experiências de vida através da sua perspectiva, da sua subjetividade.

O método biográfico tradicional optava pelos materiais biográficos secundários que eram mais objetivos, na pesquisa, trata-se da separação entre o sujeito (pesquisador) e o objeto (pesquisado) e essa não é a perspectiva do método (auto)biográfico. Assim, para Souza (2007, p. 68) "Os relatos somente são relevantes porque respondem à historicidade e subjetividade dos sujeitos em suas itinerâncias e formação".

\section{Narrativas de vida, experiência e formação}

A universidade é um espaço socioeducativo que possibilita que os estudantes construam as suas histórias de vida, seja nas salas de aulas, seja nos projetos de extensão e de pesquisa ou em outros de seus espaços (praças de convivência, bibliotecas, refeitórios, entre outros). Para a construção deste artigo, como já dito anteriormente, ouviu-se narrativas de vida de ex-estudantes que participaram como bolsistas - voluntários ou não - de IC do projeto de pesquisa do Naforme, intitulado A travessia da formação em Jornalismo: narrativas de vida e experiência em curso, para investigar a seguinte proposição: no que as experiências adquiridas nesse espaço de aprendizagem imbricaram em sua formação, na escolha dos temas e no desenvolvimento de seus TCCs.

A IC é um programa de formação e qualificação vista como uma prática importante nas instituições de ensino superior; pois oferece ao estudante da graduação a sua primeira proximidade com a pesquisa científica, já que esse realiza, geralmente, uma investigação detalhada de um determinado tema/objeto com o auxílio do seu professor orientador, o qual tem a função de acompanhá-lo durante esse período. Cabrero e Costa (2015, p. 112), definem que:

Com a IC o estudante continua com o processo informativo, entretanto, participa e contribui com a construção do pensamento da sociedade ou da apresentação de resultados que colaborem com a evolução do conhecimento. A IC não pode ser vista como especialização precoce, uma vez que não retira os estudantes da etapa de formação realizada durante a graduação, e sim estimula um forte engajamento nos estudos.

A IC ainda permite que o estudante desempenhe a sua autonomia, pois, ainda que a pesquisa seja um dos pilares da universidade, junto com o ensino e a extensão, a passagem pela IC não é obrigatória nas instituições de ensino superior. Então, o estudante, ao decidir participar dessa atividade, é por escolha própria, é a sua vontade de aprender a fazer pesquisa e de trilhar o caminho da ciência. A IC não é somente para estudantes que têm interesse em seguir carreira na área acadêmica, mas também para aqueles que sentem motivados de experimentar o fazer científico e de estar em contato com conhecimentos que são ofertados além dos conteúdos curriculares, nas salas de aulas. A passagem na IC também contribui para que o universitário tenha mais familiaridade com a linguagem acadêmica, o que pode facilitar quando ele for escrever o TCC.

Larrosa (2002, p. 21) propõe que a educação seja pensada por meio da experiência, visto que a experiência "é o que nos passa, o que nos acontece, o que nos toca". Nesse sentido, a experiência contribui para que a pessoa possa compreender e pensar no seu processo de formação, porém, não é a formação no sentido de apenas formar uma pessoa, ter um 
diploma, mas o de ser um sujeito consciente de seu ininterrupto estágio de aprendizagem. Desse modo, as narrativas de vida de pessoas em formação contam sobre os processos que influenciam suas identidades. E, para Josso (2010), são suas próprias histórias narradas que apontam percursos que irão auxiliá-las a compreender com clareza as próprias aprendizagens e o acontecer de seu processo de formação.

Os ex-estudantes entrevistados para esta pesquisa recorrem à memória individual, que segundo Halbwachs (1990), é antes, coletiva, uma vez que as memórias individuais são construídas no coletivo, pois mesmo quando aquele que a constrói está sozinho num ambiente, numa determinada situação, por exemplo, esse nunca se está só, por haver outros que povoam o seu ser no mundo. Para Halbwachs (1990), a memória individual emerge com e a partir da memória coletiva, visto que as recordações são concebidas dentro de um determinado grupo. Ainda que seja construída a partir de vivências pessoais e de situações que ocorreram coletivamente, as lembranças podem ser interpretadas por cada um à sua maneira.

Desse modo, os pesquisados ao acessarem as memórias de seus percursos formativos na IC contam não aquilo que lhes foi ensinado durante a sua vivência neste tempo, mas o que ficou de aprendizado, o que chamam de experiências formativas. Então, a vivência, de acordo com Josso (2010), se tornará uma experiência formadora, pois a reflexão que é realizada sobre o que aconteceu aos estudantes e como essa experiência os afetou, resultam num saber, e em saberes. Assim, como diz Larrosa (2002, p. 25), “A experiência e o saber que dela deriva são o que nos permite apropriamo-nos de nossa própria vida". Nessa perspectiva, os ex-estudantes ao narrativizarem as suas histórias de vida, estão se apropriando de sua pró- pria vida, e ao revisitar as suas experiências de vida, estão compreendendo e identificando as vivências que foram formativas.

Segundo Josso (2010), para considerar uma experiência como formadora é preciso colocá - la na perspectiva da aprendizagem, pois ela representa comportamentos, atitudes, pensamentos e sentimentos. Dessa maneira, Josso (2010, p. 48), declara que:

Falar das próprias experiências formadoras é, pois, de certa maneira, contar a si mesmo a própria história, as suas qualidades pessoais e socioculturais, o valor que se atribui ao que é 'vivido' na continuidade temporal do nosso ser psicossomático. Contudo, é também um modo de dizermos que, neste continuum temporal, algumas vivências têm uma intensidade particular que se impõe à nossa consciência e dela extrairemos as informações úteis às nossas transações conosco próprios e/ou com o nosso ambiente humano e natural.

Nessa perspectiva, as suas vivências particulares podem ser chamadas de experiências a partir do momento que há uma reflexão sobre elas, o que foi observado, percebido e sentido, se essa análise não for realizada, continuará só sendo as suas vivências. Para um maior entendimento sobre a concepção de experiência, Josso (2010) a classifica em três formas. A primeira é ter experiência, que é o processo de passar por situações em sua vida que foram importantes, mas não provocadas. O segundo é fazer experiências, que são os acontecimentos que foram provocados por meio das próprias pessoas, com o intuito de criar experiências. A terceira, é pensar sobre as experiências, tanto aquelas que não foram provocadas, quanto aquelas que foram criadas. De acordo com Delory-Momberger (2008), para analisar essas histórias de vida, o estudante precisa fazer uma narrativa de si, para entender as suas experiências vividas durante a sua trajetória, podendo usar a narração como um meio para a sua formação. 
Na pesquisa sobre narrativas de vida e adolescência, Paiva (2018) cita Platão para explicar o conceito de diegesis (narrativa). Para o filósofo, é considerado uma narrativa uma pessoa que fala de si mesmo, das suas compreensões sobre a vida, que não busca ser um outro alguém. Nesse sentido, mesmo que essa pessoa fale de coisas que ouviu de outras, ela contará a partir do seu entendimento e não exatamente da forma como foi dito. Para tecer afirmações sobre as narrativas de vida, Paiva (2018), ainda, faz uma referência a Genette (2009), ao dizer que, mesmo que as pessoas estejam narrando as suas próprias histórias de vida a partir de acontecimentos que são considerados reais, para elas, ainda não contemplam toda a realidade, pois estão sujeitas às suas subjetividades. Assim, para Paiva (2018, p. 212):

Se trouxermos o questionamento anterior para as narrativas de histórias de vida, seria possivel concluir que as narrativas de histórias de vida (I) são representações verbais (logos) de lembranças, como representações mentais (II), que só são passiveis de serem acessadas pelo reconhecimento - por aquele que narra ou confronta - dos signos que representam e compõem sua memória.

A partir desse trecho, Paiva (2018) esclarece sobre como a compreensão de si surge nessas representações, por meio de interpretações, uma vez que compreender-se é interpretarse. Esse sentido de compreensão advindo das hermenêuticas filosóficas gadamerianas (GADAMER, 1997) é utilizado aqui para falar que ao reconhecer-se sabendo que se sabe de si e o que se sabe de si; que se sabe algo, alguma coisa ou alguém, compreende-se que viver é interpretar o mundo. Assim como as vivências são interpretações de si. Para Paiva (2018, p. 84), “Interpretar é compreender [e vice-versa], e compreender é um movimento consciencial formativo porque compreender é, antes de tudo, compreender-se". Dessa forma, seja a re- presentação mental, verbal, todas serão realizadas mediante a interpretação, que é também a compreensão. Paiva (2018, p. 214) faz referência a Gadamer (1997) para afirmar que, "Tudo o que pode ser compreendido é linguagem". Nessa perspectiva, toda compreensão resulta da possibilidade que se tem de representar algo, seja de forma verbal ou não, mesmo que só para si mesmo.

Delory-Momberger (2008) também é citada por Paiva (2018), ao tecer estudos sobre a heterobiografia que corroboram com as teorizações de Gadamer (1997). Nesse sentido, segundo Paiva (2018), há formação pela heterobiografia uma vez que a pessoa se coloca à disposição para escutar a outra, e a partir disso, em algum momento, se identificar com o que está sendo narrado por ela. Entretanto, pode ocorrer um problema na compreensão das palavras entre a pessoa que narra e a que ouve. Isso ocorre não por conta do pouco domínio da linguagem narrativa, mas porque falta um acordo exato sobre o que se narra, como acontece em uma conversação. Para Gadamer (1997, p. 561), “A conversação é um processo pelo qual se procura chegar a um acordo. Faz parte de toda verdadeira conversação o atender realmente o outro, deixar valer seus pontos de vista e pôr-se em seu lugar [...]". É nesse processo dialogal, no qual não se intenta impor nem delinear seus pontos de vista sobre os do outro, que há a possibilidade do acontecer da heterobiografia: a escuta atenta, aberta, sem julgamentos negativos para com aquele que narra, sem imposição de verdades. A formação por meio da escuta da narrativa de vida do outro acontece quando aquele que ouve se sujeita a ouvir atentamente e a se ouvir, a retomar suas próprias experiências ao ouvir as experiências do outro, o que acontece sem nenhum esforço, além do da escuta, uma vez que a narrativa por si só é catártica. 
Paiva (2018), dialoga com Delory-Momberger (2008) para afirmar que, a formação pela heterobiografia, é "a escrita de si pela narrativa de Outro", e ela pode acontecer por meio de inúmeras formas de representações ou interpretações de si. Isso decorre não porque a pessoa que está se compreendendo está vivendo a vida do outro, mas porque ela se identifica com as narrativas de vida contadas por esse outro alguém. Na heterobiografia, a formação acontece a partir da escuta da narrativa de vida do outro. Nessa perspectiva, Paiva (2018, p. 215), afirma que:

Nessa continuidade, é no experimentar os sentidos, das experiências de vida, denotadas em forma de interpretação da compreensão de si de um Outro, na narrativa do curso de sua vida, que as experiências de sentidos possiveis de serem experienciadas por aquele que ouve, e que emergem nesse processo linguístico, se formam. Então, é possível dizer que é com e nesse processo linguístico que a compreensão de si acontece, pela heterobiografia.

Segundo Paiva (2018), a formação ocorre de forma independente e autônoma e só acontece quando a pessoa aprende algo do que foi proposto a ela, ou do que conseguiu compreender do vivido, independente do espaço em que isso aconteceu. Para tanto, essa aprendizagem depende do querer dessa pessoa, que pode ou não se dar conta do seu processo formativo. Para Paiva (2018, p. 44), “Formar-se pressupõe que, a partir de então, em um determinado aspecto, há a possibilidade de autonomia daquele que aprendeu". E foi essa autonomia que levou os quatro ex-estudantes aqui pesquisados - Agulhas Negras, Monte Roraima, Pedra Azul e Pedra do Céu - a fazer parte da IC, com o objetivo de acrescentar conhecimentos para a sua formação. Nesse contexto, como é proposto por Nóvoa no prefácio do livro de Josso ao afirmar que "[...] ninguém forma ninguém [...]" (NÓVOA, 2004, p. 15), coube a esses ex-es- tudantes buscar ser donos de suas trajetórias e de transformar esses conhecimentos adquiridos tanto em sala de aula, quanto na IC, em experiências formativas.

\section{Narrativas de si}

Para a compreensão sobre como participar da IC imbricou na escolha de tema e desenvolvimento do TCC dos quatro ex-estudantes AguIhas Negras, Monte Roraima, Pedra Azul e Pedra do Céu, foi necessário fazer uma entrevista aberta com cada um deles. O objetivo dessa conversa foi o de viabilizar que os pesquisados contassem sobre o que compreendem da IC; sobre as experiências vivenciadas durante a passagem pelo grupo de estudos e pesquisa Naforme; sobre a importância da IC no percurso formativo na/da universidade; se a escolha do tema do TCC teve relação com assuntos e autores abordados na IC e, por fim, se participar da IC contribuiu para o desenvolvimento do TCC e nas compreensões sobre o tema escolhido.

Em entrevista, os quatro ex-estudantes contaram que a pesquisa é um dos três pilares que compõe a universidade, junto com o ensino e a extensão, sendo de tamanha importância na sua vida acadêmica; no sentido de ampliar o conhecimento, de começar a se tonar pesquisador e de ter uma experiência mais completa na/da universidade, por meio da pesquisa científica.

Agulhas Negras acredita que a IC é uma porta de entrada para a pesquisa acadêmica e de grande importância para a formação dos estudantes, não só na preparação para a vida docente, mas uma formação para a vida. Monte Roraima declara que a IC é importante porque é uma forma do estudante se ver fazendo pesquisa, de produzir conhecimento e que também facilita caso a pessoa queira fazer um mestrado e continuar trabalhando no 
meio acadêmico. Pedra Azul compreende que a IC abre um leque maior de oportunidades e permite que a pessoa tenha um poder de autonomia maior sobre a sua própria formação. Já Pedra do Céu, afirma que a IC é uma experiência enriquecedora porque amplia os horizontes de conhecimento dos estudantes.

Os pesquisados ainda contam sobre como foi fazer a IC no Naforme e as experiências vividas durante a passagem deles pelo grupo de estudos e pesquisa. Antes de começar a cursar o ensino superior, Agulhas Negras acreditava que a universidade era um local que formava pessoas para serem profissionais, mas se deu conta de que a técnica podia ser aprendida em qualquer lugar. Desse modo, ao fazer a IC no Naforme, ela mudou a sua visão sobre isso e que a teoria é muito importante para a formação "A gente tinha essa liberdade de pensar, de errar, né? De aprender com o Outro, era tudo de uma maneira muito humilde". Monte Roraima diz que antes de começar efetivamente a fazer pesquisa, o grupo de estudos já era muito formativo para ela porque aprendeu sobre outros assuntos, a partir de leituras e debates, mas que foi no decorrer da IC que ela conseguiu passar esses conhecimentos para o papel: “Eu pude perceber a minha formação acontecendo, porque eu estava utilizando aquilo que eu aprendi, de certa maneira, e isso foi muito importante para mim". Pedra Azul declara que tinha poucas noções sobre métodos e técnicas de pesquisa e devido ao Naforme foi possivel compreender melhor: "Foi extremamente formativo para mim, não só como pesquisador, mas também como ser humano, porque você quando pesquisa pessoas, você aprende com o Outro". Pedra do Céu fala que ao participar do projeto do Naforme, conseguiu compreender que tudo o que estudava no grupo de pesquisa estava relacionado: “Eu não só passei pelo projeto ou pela Iniciação
Científica, essa experiência me transformou e me formou de alguma forma. Eu não saí desse projeto do mesmo jeito que entrei".

Ao serem perguntados sobre como participar da IC contribuiu para as suas trajetórias na universidade e de como ela ajudou a ampliar os horizontes, os quatro ex-estudantes afirmam que mudou a forma como enxergam o mundo e as coisas. Agulhas Negras conta que em relação a ampliar os horizontes foi de ter essa compreensão da importância da universidade e do quanto ela transforma e enriquece a vida das pessoas: "A Iniciação Científica fez eu me encontrar, em algum momento, no curso [de Jornalismo da Uesb]". Monte Roraima acredita que a IC amplia os horizontes quando você está fazendo discussões com o seu orientador e colegas e um vai formando o outro, compartilhando conhecimentos e aprendizados: “Esse é o movimento que faz com que a gente aprenda e reaprenda, construa caminhos e reconstrua, vivendo num círculo mesmo de conhecimento e aprendizado". Pedra Azul afirma que amplia no sentido de que o aluno não fica preso a sala de aula, podendo aprimorar a formação, não só como profissional, mas também como pesquisador. "É o caminho inicial que o estudante tem a possibilidade de traçar para a sua formação como pesquisador". Pedra do Céu compartilha que a IC:

Amplia os nossos horizontes de conhecimento, estimula o senso crítico e a vontade de aprender, faz com que a gente reflita sobre as nossas carências e também permite que a gente crie laços com outras pessoas que estão passando pelo mesmo processo de formação que nós. (Narrativa Pedra Azul)

Para responder à questão norteadora deste artigo, interrogamos os pesquisados sobre quais foram os seus temas de TCCs e se esses tiveram alguma relação com as suas passagens pela IC. O tema do TCC de Agulhas Negras foi Prática Jornalística e Formação, voltado 
para o ambiente da escola, e como essa prática jornalística contribuiu para a formação de estudantes do ensino médio. Para tanto, realizou-se uma pesquisa em uma escola estadual da cidade de Barra da Choça, na Bahia, em que estudantes do turno noturno produziam anualmente um jornal para a escola. Agulhas Negras ainda declara que sempre gostou de falar sobre educação e no decorrer do projeto da IC, que pesquisavam e discutiam sobre educação e formação, ela se identificou por ser um tema que lhe era instigante: "Acho que o projeto de pesquisa e Iniciação possibilitaram que eu aprendesse mais sobre [educação e formação], e eu me descobri ali né, descobri que eu realmente gostava daquilo e isso direcionou para o [tema do] meu Trabalho de Conclusão de Curso". Ao ser perguntada se a IC contribuiu para a sua escolha de TCC, Agulhas Negras afirma: "Eu digo que a Iniciação Científica praticamente viabilizou né, por conta das leituras que eu tive na IC, por conta das vivências na IC, eu acho que foi praticamente o que tornou meu tema viável, que eu conseguisse, né? Desenvolver o tema do meu TCC".

Monte Roraima conta que o seu tema de TCC foi "Experiência de vida e formação na práxis jornalístico-literário de Eliane Brum", em que a estudante pretendeu perceber como as histórias, experiências de vida e formação do jornalista estão imbricadas na sua práxis. Nesse sentido, segundo Monte Roraima, são as experiências e a formação desses jornalistas que vão direcionar o olhar deles para a escotha de uma pauta jornalística, porque aquilo que está guardado no arquivo de memória da pessoa que irá conduzi-la a escolha do assunto a ser pautado. Monte Roraima declara que a escolha de seu TCC estava inteiramente relacionada com a sua passagem na IC e no Naforme, visto que foram nesses ambientes que ela estudou sobre as narrativas de vida, experiência e formação e também memória, voltados para o jornalismo, assuntos que guiaram o seu TCC. "A gente pode fazer essa interdisciplinaridade dentro da academia né, trazer estudos que são da área de educação, para o jornalismo, para gente ter um conhecimento ampliado sobre a nossa própria práxis. A gente não precisa ficar restrito aquilo que dizem que é para gente utilizar de metodologia", afirma Monte Roraima. Ela ainda cita os autores que utilizou no TCC, todos vistos durante sua passagem pelo Naforme, como Bertaux, Delory-Momberger, Gadamer, Larrosa, entre outros.

O tema de TCC de Pedra Azul foi "A narrativa de si como dispositivo de formação: um entrelace de experiências biográficas com e a partir do fazer jornalístico no Instagram Stories". Pedra Azul diz que também utilizou o método (auto)biográfico das histórias de vida para trabalhar em sua pesquisa, que é a formação pela escuta de narrativas do outro. 0 intuito do TCC era compreender como as suas narrativas de vida, enquanto estudante de Jornalismo na UESB e a sua produção jornalística realizada no Instagram, poderiam atuar como dispositivo de formação para os seus colegas de curso. Pedra azul ainda fala que o seu TCC teve relação direta com a sua passagem na IC:

Eu utilizei a mesma metodologia e o mesmo método empregado no projeto de pesquisa do qual eu fui bolsista, né? Na IC. Então, eu já tinha esse contato com o método e com a metodologia que eu utilizei e com discussões teóricas e metodológicas com as quais eu empreguei e trabalhei as minhas teorizações, lá na monografia.

O estudante ainda afirma que os livros e autores que estudou na IC, como Josso, Nietzsche, Nóvoa e Finger, o ajudaram a ter um conhecimento sobre o método (auto)biográfico e a metodologia de pesquisa-formação heterobiográfica, usados em seu TCC.

Já Pedra do Céu revela que o seu tema de TCC "As agências de checagem brasileiras que 
tentam combater as Fake News", não teve relação com os assuntos que ela estudou na IC e no Naforme. “O único grupo de pesquisa do qual participei foi o Naforme, e por isso, imaginei que faria um trabalho usando temáticas mais próximas do grupo, como memória ou formação. Mas no final das contas, eu acabei indo para uma direção completamente diferente". Pedra do Céu disse que no sexto e sétimo semestres teve um contato maior com mídias sociais e fake news, visto que foram assuntos abordados na disciplina de Jornalismo Digital. Assim, ela começou um projeto para o site da disciplina, o Avoador, ${ }^{3}$ com a editoria de checagem de fatos chamada Xereta, no qual era editora, e passou a se interessar e ter mais afinidade por esses assuntos. "Digamos assim, eu não me dediquei tanto as leituras como eu deveria, e mesmo me dedicando também, não sei, não sentia que era algo que eu gostaria de usar no meu trabalho de conclusão de curso que era uma coisa que eu ia levar muito tempo e que então teria que ser algo que eu realmente gostasse de estudar".

Pedra do Céu ainda explica que a professora responsável pela disciplina de Jornalismo Digital, passou a ser a sua orientadora para o TCC. Ainda assim, a ex-estudante reafirma a importância de ter participado da IC: “Quando eu assistia todas aquelas entrevistas, eu conseguia me ver nas falas de muitas pessoas. Então, eu realmente senti que estava me formando ao estudar sobre a formação do outro". Apesar de afirmar que foi um caminho totalmente diferente do que ela esperava, a sua passagem na IC a ajudou a fazer o seu TCC. "A IC contribuiu para a construção do meu TCC porque fez com que eu me responsabilizasse pela minha formação e isso, de certa forma, me levou até o meu tema".

Os quatro ex-estudantes ainda contam se a IC contribuiu para o desenvolvimento de seus

3 Link para acessar o site do Avoador: https://avoador. com.br/.
TCCs e a forma como compreendem os temas escolhidos. Agulhas Negras conta que ajudou na escrita, uma vez que o referencial teórico utilizado em seu TCC, boa parte foi visto na IC. Ainda fala que se tivesse se empenhado mais na IC teria facilitado ainda mais esse processo: "Se eu tivesse desenvolvido, eu acredito, mais trabalhos durante a Iniciação Científica, porque não cheguei a finalizar nenhum artigo da Iniciação Científica, eu acho que teria sido mais fácil para o meu percurso [no TCC]". Monte Roraima afirma que facilitou no desenvolvimento, visto que já tinha estudado os autores que ela teorizou em seu TCC, então, só teve que revisitá-los para ampliar o seu conhecimento e compreensão acerca do tema:

A forma como eu vejo o tema foi totalmente moldada, a partir das minhas experiências no Naforme, porque se eu não tivesse participado do Naforme, eu não saberia os conceitos, as conceituações de formação das narrativas de vidas e experiência e eu não iria conseguir perceber isso no tema de Jornalismo. (Narrativa Monte Roraima)

Pedra Azul afirma que a IC facilitou na escrita do seu TCC porque ele já tinha praticado a escrita acadêmica na iniciação e isso contribuiu no desenvolvimento do TCC. Ele ainda fala que por ter sempre produzido os seus artigos em terceira pessoa, se permitiu escrever em primeira pessoa a sua monografia, uma vez que ele iria falar das suas próprias experiências de vida. Ele afirma que foi muito formativo escrever em primeira pessoa do singular e praticar o rigor da escrita científica ao mesmo tempo. Sobre ter revisitado os autores que estudou durante a sua IC, Pedra azul declara "A gente não deixa de saber e de conhecer mais, quanto mais a gente faz, né? Quanto mais a gente busca aprender sobre! Então, eu aprendi muito e muito mais sobre o método (auto)biográfico, sobre a pesquisa-formação heterobiográfica, durante o TCC". Já Pedra do Céu conta 
que, mesmo que a escolha de tema do seu TCC não tenha relação com os autores e livros estudados por ela, no Naforme e IC, acredita que o contato anterior com a pesquisa acadêmica proporcionada pela IC, como também as disciplinas que teve durante o seu curso, a preparou para a escrita de sua monografia.

\section{Considerações Finais}

No decorrer desta pesquisa, foi possivel compreender como a participação em um projeto de IC contribuiu para formação dos ex-estudantes pesquisados, ao ampliarem seus conhecimentos acerca da temática estudada e ao produzirem conhecimentos por meio de artigos científicos, na IC, e em seus TCCS, ao explorarem a universidade enquanto espaço de aprendizagem. Pelas narrativas desses ex -estudantes, pudemos constatar como participar de um grupo de estudos e pesquisa faz com que o estudante direcione a sua atenção a assuntos que são do seu interesse, se aprofundando no tema e dialogando conhecimento com os colegas e orientador.

Um outro ponto que consideramos importante nesse processo de escuta das narrativas de formação dos pesquisados é que a formação acontece - na maioria das vezes, quando se trata especificamente da formação acadêmica - de forma lenta; pois é uma construção, na qual, a heterobiografia participa quase que de forma permanente, visto que é preciso nos colocar à disposição para escutarmos a(s) narrativa(s) do(s) outro(s). Ao utilizar o método (auto)biográfico para a realização deste artigo, estávamos nos formando e ao mesmo tempo propondo uma formação para os pesquisados também, pois quando eles param para refletir e narrar sobre as experiências vivenciadas na IC, eles estavam se dando conta de seus processos formativos. Ao ouvi-los, nos formamos também, porque passamos a nos identificar com os depoimentos dos pesquisados, no sentido de perceber que tivemos pensamentos e dúvidas parecidas enquanto participantes e pesquisadores da IC. Esta pesquisa também possibilitou que os ex-estudantes pudessem relembrar como decidiram o tema de seus TCCs e qual caminho cada um tomou para realizar as suas pesquisas.

Ao pararem para pensar se há relação ou não dos temas escolhidos para desenvolverem em seus TCCs com os estudos realizados na IC do Naforme, os pesquisados se colocaram enquanto autores de sua própria jornada no curso de Jornalismo da UESB ao produzirem, como diz Souza (2007, p. 69), "um conhecimento sobre si, sobre os outros e o cotidiano, revelando-se através da subjetividade, da singularidade, das experiências e dos saberes". Assim, por meio das narrativas de histórias de vida, que abarcam o decurso de suas vivências na IC, no Naforme e na escolha e desenvolvimento de seus TCCS, os ex-estudantes nos possibilitaram compreender que a autonomia ou a falta dela participam do processo formativo humano e acadêmico e que, o método (auto) biográfico funciona como dispositivo de formação. Bem como ficou claro que participar de grupo de estudos e fazer IC, na graduação, traz implicação e provoca os envolvidos na busca de uma autonomia (auto)formativa.

\section{Referências}

CABRERO, Rodrigo de Castro; COSTA, Maria da Piedade Resende da. Elementos e sujeitos que constituem a experiência da iniciação científica. In: MASSI, Luciana; QUEIROZ, Salete (orgs.) Iniciação Científica: aspectos históricos, organizacionais e formativos da atividade no ensino superior. São Paulo: Editora UNESP, p. 109-129, 2015. Disponivel em: http:/ / books. scielo.org/id/s3ny4/pdf/massi-9788568334577-06. pdf. Acesso em: 16 mai. 2020.

DELORY-MOMBERGER, Christine. Biografia e educação: figuras do indivíduo-projeto. Prefácio Pierre 
Dominicé; Tradução de Maria da Conceição Passeggi, João Gomes da Silva Neto, Luis Passeggi. Natal, RN: EDUFRN; São Paulo: Paulus, 2008.

FERRAROTTI, Franco. Sobre a autonomia do método biográfico. In: NÓVOA, António; FINGER, Matthias. (Orgs.). 0 método (auto)biográfico e a formação. Natal: EDUFRN; São Paulo: Paulus, 2010. p. 33-57.

FINGER, Matthias. (Orgs.). 0 método (auto)biográfico e a formação. Natal: EDUFRN; São Paulo: Paulus, 2010.

GADAMER, Hans-Georg. Verdade e Método: traços fundamentais de uma hermenêutica filosófica. Tradução de Flávio Paulo Meurer. 3á ed. Petrópolis, RJ: Vozes, 1997.

GENETTE, Gérard. Nouveau discours du récit. Paris: Seuil, 1983.

HALBWACHS, Maurice. A Memória Coletiva. Trad.: de Laurent Léon Schaffter. São Paulo: Edições Vértice, 1990.

JOSSO, Marie-Christine. Experiência de vida e formação. Natal: EDUFRN; São Paulo: Paulus, 2010.

LARROSA, Jorge. Notas sobre a experiência e o saber de experiência. Revista Brasileira de Educação, Rio de Janeiro, n. 19, p. 20-28, jan./fev./mar./abr., 2002.
Disponível em: https://www.scielo.br/pdf/rbedu/ n19/n19a02.pdf. Acesso em: 10 ago. 2018.

NÓVOA, António. Prefácio. In: JOSSO, Marie-Christine. Experiência de vida e formação. Natal: EDUFRN; São Paulo: Paulus, 2010. p. 07-17.

PAIVA, Élica. Narrativas de histórias de vida como formação de si: um jogo com adolescentes do povoado do Maracujá. Lisboa: Chiado Editora, 2018.

A travessia da formação em Jornalis-

mo: narrativas de vida e experiência em curso. Universidade Estadual do Sudoeste da Bahia - Uesb. Resolução CONSEPE no. 031/2016.

PASSEGGI, Maria da Conceição. A Experiência em Formação. Educação, Porto Alegre, PUCRS, v. 34, no 2, p. 147-156, maio/ago., 2011. Disponivel em: http:// revistaseletronicas.pucrs.br/ojs/index.php/faced/ article/viewFile/8697/6351. Acesso em: 4 jun. 2019.

SOUZA, Elizeu Clementino. (Auto)biografia, histórias de vida e práticas de formação. Salvador: Edufba, 2007.

Recebido em: 06.01.2020

Revisado em: 17.05.2020

Aprovado em: 31.05 .2020

Fernanda Nogueira Macena é graduanda em Jornalismo na Universidade Estadual do Sudoeste da Bahia (UESB). Integrante do projeto de pesquisa Narrativas, Formação e Experiência (Naforme).E-mail: fernanda.nogueira.macena@ gmail.com

Élica Luiza Paiva é doutora em Educação pela Faculdade de Educação (Faced) da Universidade Federal da Bahia (UFBA). Professora adjunta do curso de Jornalismo da Universidade Estadual do Sudoeste da Bahia (UESB). Coordenadora do projeto de pesquisa Narrativas, Formação e Experiência (Naforme).E-mail: elica.paiva@uesb.edu.br 